\title{
Analysis of Filler Particle Levels and Sizes in Dental Alginates
}

\author{
Hugo Lemes Carlo ${ }^{\mathrm{a}}$, Rodrigo Borges Fonseca ${ }^{\mathrm{b}}$, Luciano de Souza Gonçalves ${ }^{\mathrm{d}}$, \\ Lourenço Correr-Sobrinho ${ }^{\mathrm{d}}$, Carlos José Soares ${ }^{\mathrm{c}}$, Mário Alexandre Coelho Sinhoreti ${ }^{\mathrm{d}}$ * \\ ${ }^{\mathrm{a}}$ Department of Restorative Dentistry, Health Sciences Center, \\ Federal University of Paraíba-UFPB, João Pessoa, PB, Brazil \\ ${ }^{\mathrm{b}}$ Department of Rsrtorative Dentistry, Goiania School of Dentistry, \\ Federal University of Goias - UFG, Goiania, GO, Brazil \\ 'Operative Dentistry and Dental Materials Division, Uberlândia School of Dentistry, \\ Federal University of Uberlândia - UFU, Uberlândia, MG, Brazil \\ 'Department of Restorative Dentistry, Dental Materials Division, Piracicaba Dental School, \\ University of Campinas - UNICAMP, Piracicaba, SP, Brazil
}

Received: February 10, 2010; Revised: April 23 ,2010

\begin{abstract}
The aim of this study was to determine the inorganic filler fractions and sizes of commercially alginates. The inorganic particles volumetric fractions of five alginates - Jeltrate(J), Jeltrate Plus(JP), Jeltrate Chromatic Ortho(JC), Hydrogum(H) and Ezact Krom(E) were accessed by weighing a previously determined mass of each material in water before and after burning samples at $450{ }^{\circ} \mathrm{C}$ for 3 hours. Unsettled materials were soaked in acetone and chloroform and sputter-coated with gold for SEM evaluation of fillers' morphology and size. The results for the volumetric inorganic particle content were (\%): J - 48.33, JP - 48.33, JC - 33.79, H - 37.55 and E - 40.55. The fillers presented a circular appearance with helical form and various perforations. Hydrogum fillers looked like cylindrical, perforated sticks. The mean values for fillers size were $(\mu \mathrm{m}) \mathrm{J}-12.91, \mathrm{JP}-13.67$, JC - 13.44, E - 14.59 and $\mathrm{H}-9$ (diameter), 8.81 (length). The results of this study revealed differences in filler characteristics that could lead to different results when testing mechanical properties.
\end{abstract}

Keywords: dental impression materials, alginate, scanning electron microscopy, filler

\section{Introduction}

Impression materials are used in dentistry for pre-treatment planning, fabrication of fixed or removable prostheses and post-treatment records ${ }^{1,2}$. These materials can be allocated into two categories: elastic and inelastic. Elastic impression materials return to their original configuration after being removed from undercuts in the mouth due to elastic recovery ${ }^{2,3}$. Originally developed in the 1930's, alginate (irreversible hydrocolloid) is classified as an irreversible hydrocolloid material, having a wide use in dentistry due to easy manipulation, comfort to the patient, low cost, and hydrophilicity (contact angle $\left.37^{\circ}\right)^{1,3-5}$.

Alginates are commonly used as a two-component system-powder and water. The powder contains sodium or potassium alginates (soluble alginates), diatomaceous earth acting as filler particles, calcium sulfate as reactor, a fluoride as accelerator and sodium phosphate as a retarder ${ }^{3}$. The reaction does not start until the dry powder is mixed with water ${ }^{1,3}$. It is recommended to tumble the alginate powder in a closed container before use to establish uniform distribution of the material's ingredients. During this process, airborne particles form an aerosol that could be hazardous to dental professionals, causing pleural and peritoneal malignances ${ }^{6,7}$.

Irrespective of composition, certain physical properties of impression materials are required to warrant clinical success. Elastic recovery, strain in compression, compressive strength, thixotrophy, compatibility with dental stones, surface roughness, tear energy, dimensional stability and hydrophilicity are some of these important properties $^{5,8,9}$. Nonetheless, alginate has some disadvantages as it poorly reproduces surface details, it is not dimensionally stable when stored, and it is usually best poured immediately ${ }^{1-3}$.

Lim et al. ${ }^{10}$ and Beaty et al. ${ }^{11}$ showed that filler fraction affects composite resins' wear, uniaxial tensile strength, Young's modulus in slow compression, Knoop hardness, water sorption, and toothbrush abrasion resistance. Similar to composite resins, the filler fraction may also have an effect on alginate properties. Giordano ${ }^{2}$, Anusavice ${ }^{3}$ and Murata et al. ${ }^{9}$ did not make a correlation between inorganic particles and alginate properties but the authors state that filler size and content are closely related to accuracy and compressive strength results.

Therefore, the aim of this study was to investigate the filler fraction of commercial alginates. Moreover, fillers were qualitative analyzed by Scanning Electron Microscopy (SEM).

\section{Experimental}

The filler volumetric fraction, morphology and size of five commercial brands of alginate (Table 1) were analyzed as described below.

\subsection{Volumetric filler fraction}

The percentage of inorganic particle by volume was determined by calculating the difference between the mass of each material tested in air and in water (Archimedes' Principle) $)^{12}$. Materials were manipulated according to the manufacturer's instructions and placed 
in an aluminum matrix. Cylindrical specimens (12 mm diameter, $20 \mathrm{~mm}$ high) of each material were weighed in an analytical balance (JK 180, Chyo Balance Corp., Tokyo, Japan), with an accuracy of $0.0001 \mathrm{~g}(\mathrm{n}=5)$. The dried mass (Md) of the material after the setting time was determined in air. To determine the wet mass (Mi), a recipient and a stainless steel mesh were placed over the balance plate and filled with distilled water, and the specimen was immersed. The volume of the specimen after setting time was measured according to the following Equation 1:

$$
\mathrm{Vs}=\mathrm{Md}-\mathrm{Mi}
$$

The specimens were then burned in an oven (Bravac Ltda, Sao Paulo, SP, Brazil) to remove the organic phase, over 3 hours gradually increasing the temperature from room temperature to $450{ }^{\circ} \mathrm{C}$ (this temperature was previously determined in a pilot study). The resulting inorganic material was intact and pill-shaped. The mass in air (Mp) was then measured as described above. To determine the wet mass of the particles (Mpi), the specimens were immersed in distilled water as described above, and at this time the pill shape was disarranged because of the contact with water. The volume of the inorganic particles was measured according to the following Equation 2:

$$
\mathrm{Vp}=\mathrm{Mp}-\mathrm{Mpi}
$$

The percentage of the inorganic phase by volume was calculated using the following Equation 3:

$$
\text { Inorganic particle percentage }=\frac{V_{p}}{V_{s}} .100
$$

\subsection{Filler morphology and size}

The morphology of the fillers was determined by SEM images (JSM - 5600, JEOL ${ }^{\circledR}$ Ltd. Tokyo, Japan). Unsettled amounts of each material $(0.5 \mathrm{~g})$ were submitted to the washing technique ${ }^{13}$. The matrix was removed by dissolving each material in $5 \mathrm{~mL}$ of acetone and centrifuging for 2 minutes at $1000 \mathrm{rpm}$. This process

Table 1. Materials tested, manufacturer, and batch number.

\begin{tabular}{ccc}
\hline Material & Manufacturer & Batch number \\
\hline Jeltrate & $\begin{array}{c}\text { Dentsply Latin America, } \\
\text { Petropolis, RJ, Brazil }\end{array}$ & 156999 \\
Jeltrate Plus & $\begin{array}{c}\text { Dentsply Latin America, } \\
\text { Petropolis, RJ, Brazil }\end{array}$ & 288721 \\
Jeltrate Chromatic & $\begin{array}{c}\text { Dentsply Latin America, } \\
\text { Ortho }\end{array}$ & 142603 \\
Hydrogum & $\begin{array}{c}\text { Zhermack, Rovigo, } \\
\text { Italy }\end{array}$ & 21834 \\
Ezact Krom & Vigodent, Brazil \\
& Rio de Janeiro, RJ, Brazil & $078 / 05$ \\
\hline
\end{tabular}

Table 2. Mean values for volumetric filler fraction of alginates (\%).

\begin{tabular}{cc}
\hline Material & Volumetric filler fraction \\
\hline Jeltrate & 48.33 \\
Jeltrate Plus & 48.33 \\
Jeltrate Chromatic Ortho & 33.79 \\
Hydrogum & 37.55 \\
Ezact Krom & 40.55 \\
\hline
\end{tabular}

was repeated three times. The remaining material mass was next placed three times in chloroform and centrifuged as described above for a further washing and elimination of the matrix. The fillers were then smeared in aluminum stubs (13), gold-sputter coated with gold/palladium in high vacuum (SCD 050, Bal-tec AG, Liechtenstein), and examined in a Scanning Electron Microscope operating at $15 \mathrm{Kv}$.

SEM pictures were imported to the Image-Pro Plus 4.5 image analyzer software (Media Cybernetics Inc., Bethesda, MD, USA) where the images were analyzed by the measurement tool. At least twenty particles of each material were analyzed during this procedure, determining the maximum, minimum and mean diameter size. Fillers' size was determined in micrometers $(\mu \mathrm{m})$.

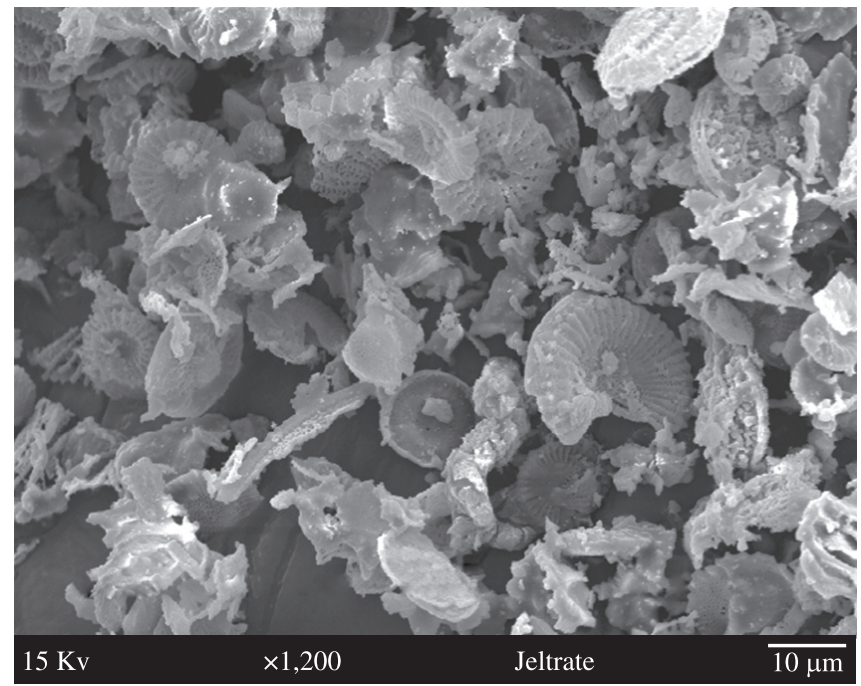

Figure 1. Typical scanning electron photomicrograph of Jeltrate inorganic fraction. Particles can be seen with several shapes and sizes, presenting a circular structure and a helical form with various perforations.

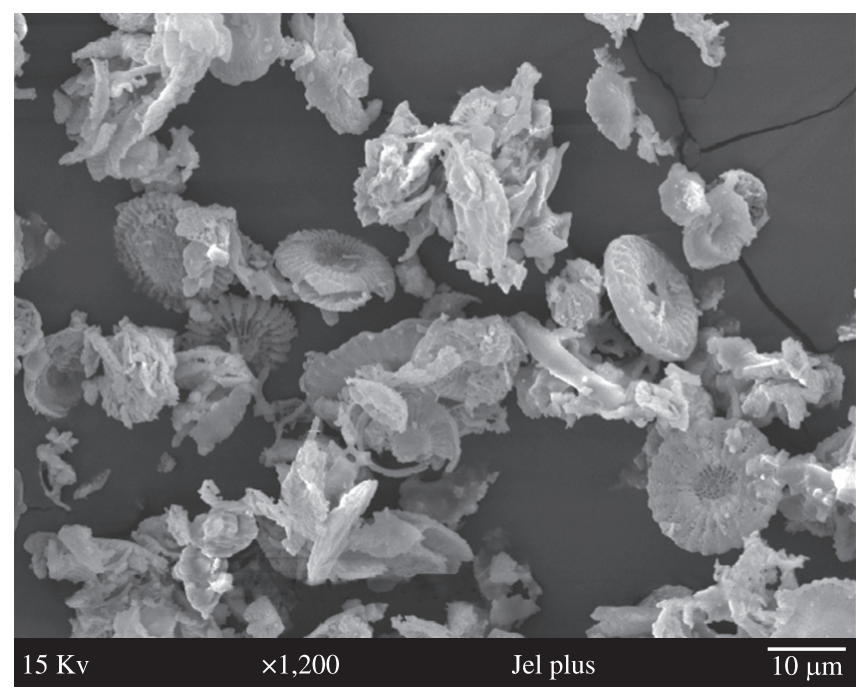

Figure 2. Typical scanning electron photomicrograph of Jeltrate Plus inorganic fraction. Just as Jeltrate, there are several particles with different shapes and sizes, predominating a helical form with various perforations. 


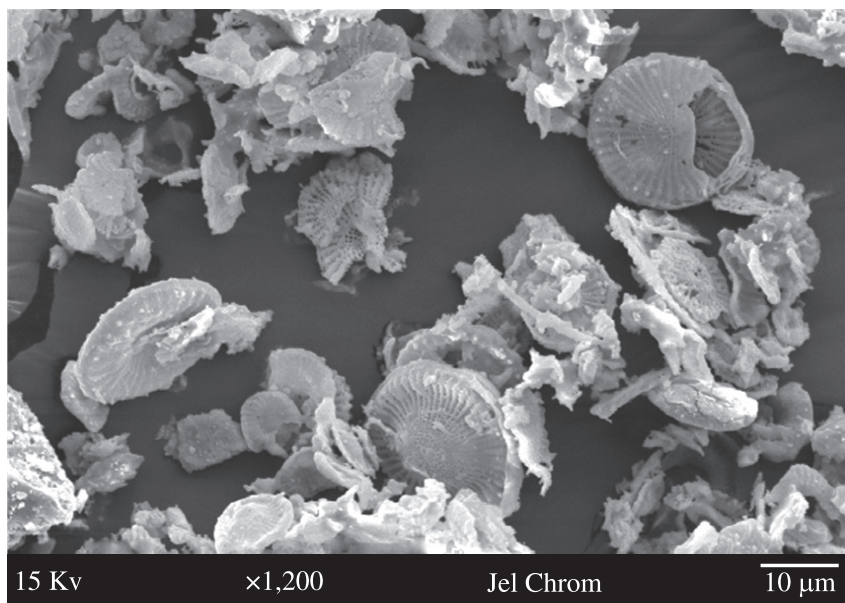

Figure 3. Typical scanning electron photomicrograph of Jeltrate Chromatic Ortho inorganic fraction. Similarly Jeltrate, particles can be seen with circular holes and smaller particles with irregular shapes. These irregular particles are probably the same circular that were broken, since the EDX examination showed the same basic composition.

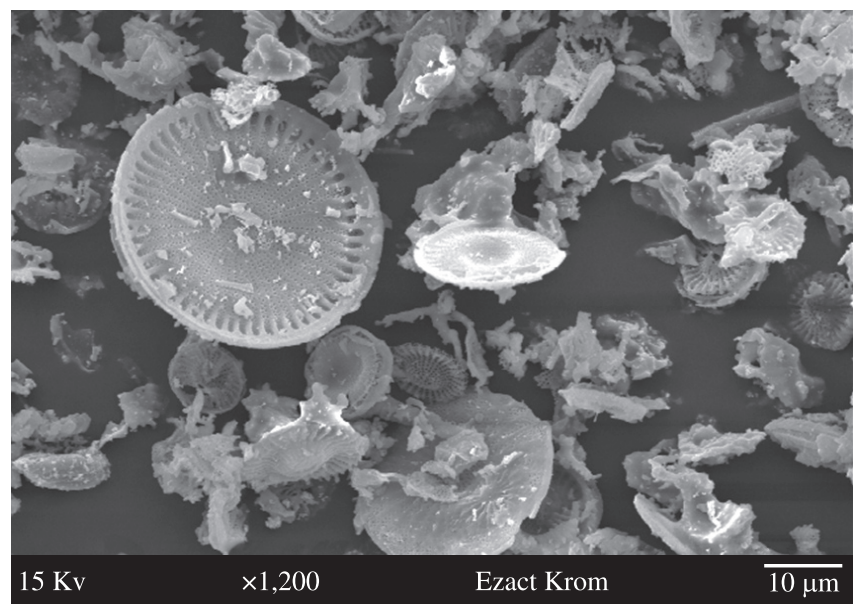

Figure 4. Typical scanning electron photomicrograph of Ezact Krom inorganic fraction. Particles can also be seen with circular holes and smaller particles with irregular shapes, probably from grinding of the circular particles.

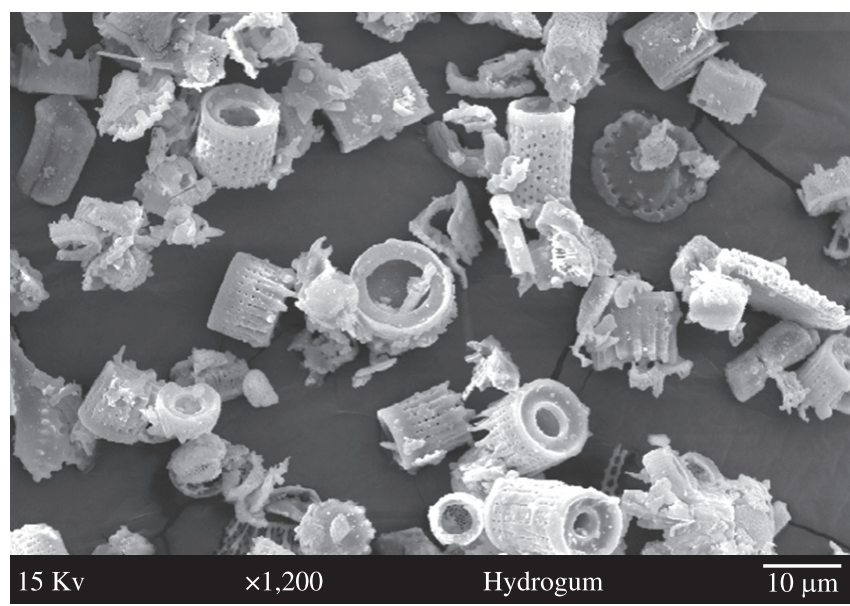

Figure 5. Typical scanning electron photomicrograph of Hydrogum inorganic fraction. Particles can be seen with several shapes and sizes, predominating cylindrical and perforated sticks.
Table 3. Maximum, minimum, and mean values for alginate filler size $(\mu \mathrm{m})$.

\begin{tabular}{cccr}
\hline Material & Maximum & Minimum & Mean \\
\hline Jeltrate & 20.93 & 7.86 & 12.91 \\
Jeltrate Plus & 17.25 & 10.73 & 13.67 \\
Jeltrate Chromatic Ortho & 21.60 & 7.28 & 13.44 \\
Hydrogum (diameter) & 13.26 & 5.19 & 9.00 \\
Hydrogum (length) & 15.25 & 5.42 & 8.81 \\
Ezact Krom & 34.92 & 8.05 & 14.59 \\
\hline
\end{tabular}

\section{Results}

\subsection{Volumetric filler fraction}

The mean values of percentage content of inorganic particles in volume are listed in Table 2. Jeltrate and Jeltrate Plus presented the highest mean values $(48.33 \%)$, while Jeltrate Chromatic Ortho presented the lowest values (33.79\%). Ezact Krom and Hydrogum showed 40.55 and $37.55 \%$, respectively.

\subsection{Filler morphology and size}

The morphology of the fillers is shown in the SEM images in Figures 1-5. The materials' inorganic particles presented several shapes and sizes. In general, materials' particles had the same appearance, with a circular structure and a helical form with various perforations. The unique exception was Hidrogum, which looked like cylindrical, perforated sticks.

The maximum, minimum, and mean diameter size values of the inorganic particles are listed in Table 3. Ezact Krom showed the highest mean values for diameter size. Because of the difference of Hydrogum particle shape, which had a considerable length to be measured, Table 3 presents its maximum, minimum and mean length values beyond the values for diameter.

\section{Discussion}

The objective of the present study was to analyze qualitatively and quantitavely the inorganic particle content of some commercial brands of alginates. The findings of this investigation showed Jeltrate Chromatic Ortho as the material with the lowest results for volumetric filler fraction (33.79\%), while Jeltrate and Jeltrate Plus had the highest values $(48.33 \%)$. Thus, it is expected that the increase of alginate on Jeltrate Chromatic Ortho will cause an alteration on stability due to the fact that gels are invariably subject to changes in dimension by syneresis, evaporation, and imbibition of water ${ }^{3}$. A study comparing dental alginates' inorganic fraction and their mechanical and physical properties was not found in the literature. Differences among materials are not directly related to filler content ${ }^{6,14}$, but it seems to be very important to be considered ${ }^{2,3,9}$.

The inorganic particles observed by SEM pictures are cell walls of algae from the division Chrysophyta, class Bacillariophycea. The members of this class, referred to as diatoms, are essentially unicellular, although chains of cells and colonial aggregations may occur $^{15}$. There are records of these algae dating from the Cretaceous Period. The classification of diatoms is almost entirely based on the structure and ornamentation of the cell wall, which is termed the frustules ${ }^{15}$. Diatom frustules are resistant to natural degradation, and their accumulation over geologic periods has resulted in significant deposits. Termed diatomaceous earth, or diatomite, this material is mined and used for a variety of commercial purposes, because of its worldwide range ${ }^{15}$. 
There are no special known interactions between fillers and gel fibrils demanding the use of diatomite as alginates inorganic fractions, and it was quite easy to separate them by the washing technique ${ }^{13}$. Possibly diatomite was chosen as an inorganic fraction because of its low $\cos ^{15}$. When added in proper amounts, it can optimize the strength and stiffness of the alginate gel, produce a smooth texture, and ensure a firm gel surface that is not tacky. It also aids in forming the sol, dispersing the alginate powder particles in water. Without the filler, the gel formed lacks firmness and exhibits a sticky surface covered with an exudate produced by synerisis ${ }^{3}$.

The size and amount of filler and the gel fibrils are related to alginate accuracy ${ }^{2,3}$. This way, it is expected that Hydrogum will be the material with the best results for detail reproduction because of its lowest mean diameter $(9 \mu \mathrm{m})$ and low results for volumetric filler fraction, while Jeltrate and Jeltrate Plus are expected to present conflicting results. There is a difference in the morphology of Hydrogum and the other materials. It seems that the diatomite in Hydrogum's composition is a colonial aggregation belonging to a different order, suborder, or genera from the other materials.

Inhalation of aerosols arising from alginates is potentially hazardous to dentists and their assistants over a long time span $^{7}$. The degree of malignance is related to the size of the fibers rather to their composition ${ }^{16}$. Particles of less than $3 \mu \mathrm{m}$ in diameter and more than $20 \mu \mathrm{m}$ in length present the greatest hazard ${ }^{17}$. Woody et al. ${ }^{7}$ monitored and characterized aerosol particles from two alginates and showed that 10 to $15 \%$ of the particles had dimensions less than $3 \mu \mathrm{m}$ in diameter and more than $20 \mu \mathrm{m}$ in length. The fillers observed in the present work vary from 34.92 to $13.26 \mu \mathrm{m}$ in diameter and from 15.25 to $5.42 \mu \mathrm{m}$ in length. Apparently, these particles would not be an etiologic factor in fibroses of the lungs. Additionally, the manufacturers attempted to produce "dust-free" alginates by incorporating additives (glycols) and suppressing the aerosol formation ${ }^{6}$.

The findings of this investigation lead to questions about inorganic filler fraction of dental alginates' correlation to their mechanical properties. It is now necessary to continue the research, answer the assumed questions, and make a suitable correlation between fillers and results for elastic recovery, strain in compression, dimensional stability, radiodensity, and detail reproduction, among other properties.

\section{Conclusion}

Within the limitations of the analyses which were done, it was concluded that there were differences in filler characteristics among the materials. Thus, Jeltrate Chromatic Ortho was the material with the lowest results for volumetric filler fraction, while Jeltrate and Jeltrate Plus had the highest values. Hydrogum had the lowest mean particle diameter and Ezact Krom the highest.

\section{Acknowledgments}

The authors would like to thank to Dentsply Latin America, Labordental and Vigodent for supplying the materials tested.

\section{References}

1. Doubleday B. Impression materials. British Journal of Orthodontics. 1998; 25(2):133-140.

2. Giordano R. Impression materials: basic properties. General Dentistry. 2000; 48(5):510-512.

3. Anusavice K. Phillips' Science of Dental Materials. $11^{\text {th }}$ ed. Philadelphia: Saunders; 2003.

4. Cook W. Alginate dental impression materials: chemistry, structure, and properties. Journal of Biomedical Materials Research. 1986; 20(1):1-24.

5. Frey G, Lu H and Powers J. Effect of mixing methods on mechanical properties of alginate impression materials. Journal of Prosthodontics. 2005; 14(4):221-225.

6. Veres E, Slabbert JC and Becker P. The effect of dust-suppressant additives on the physical properties of an irreversible hydrocolloid. Journal of Prosthetic Dentisty. 1990; 63(1):90-94.

7. Woody RD, Huget EF and Cutright DE. Characterization of airborne particles from irreversible hydrocolloids. Journal of American Dental Association. 1977; 94(3):501-504.

8. Donovan TE and Chee WW. A review of contemporary impression materials and techniques. Dental Clinics of North America. 2004; 48(2):445-470

9. Murata H, Kawamura M, Hamada T, Chimori H and Nikawa H. Physical properties and compatibility with dental stones of current alginate impression materials. Journal of Oral Rehabilitation. 2004; 31(11):1115-1122.

10. Lim BS, Ferracane JL, Condon JR and Adey JD. Effect of filler fraction and filler surface treatment on wear of microfilled composites. Dental Materials. 2002; 18(1):1-11.

11. Beatty MW, Swartz ML, Moore BK, Phillips RW and Roberts TA. Effect of microfiller fraction and silane treatment on resin composite properties. Journal of Biomedical Materials Research. 1998; 40(1):12-23.

12. Adabo GL, Dos Santos Cruz CA, Fonseca RG and Vaz LG. The volumetric fraction of inorganic particles and the flexural strength of composites for posterior teeth. Journal of Dentistry. 2003; 31(5):353-359.

13. Lang BR, Jaarda M and Wang RF. Filler particle size and composite resin classification systems. Journal of Oral Rehabilitation. 1992; 19(6):569-584.

14. Lee YK, Lim BS and Kim CW. Effect of fluoride addition on the properties of dental alginate impression materials. Journal of Materials Science: Materials in Medicine. 2004; 15(3):219-224.

15. Bold HC and Wynne MJ. Introduction to the algae. 2nd ed., Englewood Cliffs: Prentice-Hall; 1985.

16. Stanton MF and Wrench C. Mechanisms of mesothelioma induction with asbestos and fibrous glass. Journal of the National Cancer Institute. 1972; 48(3):797-821.

17. Stanton MF. Editorial: Fiber carcinogenesis: is asbestos the only hazard? Journal of the National Cancer Institute. 1974; 52(3):633-634. 